\title{
Stigma reduction through group counselling of persons affected by leprosy - a pilot study
}

\author{
MARYANN FLOYD-RICHARD* \& \\ SAMJHANA GURUNG** \\ *5 Ledbury Close, Eccleston, St Helens, Merseyside WA10 5NY, UK \\ **Counselling Department, Green Pastures Hospital, Pokhara, \\ Nepal
}

Summary Stigmatization of persons with leprosy causes the emotional harm of social, economic and spiritual deprivation. Individual counselling has benefits in addressing these psychosocial problems but is a slow process and effects few people at any one time. Our experience of group counselling of stigmatized persons achieved the following: addressing common issues to more than one person at a time, encouraging the unity of sufferers, developing compassion for others, understanding the common effects of stigmatization, and beginning to overcome its harmful effects.

\section{Introduction}

A man who is isolated and alone can be regarded as a sort of discarded person. He is a man cast out of society, and that type of man, in the old days, would have been killed. Let me say this - and I say it very seriously: there is nothing worse than being isolated.

Dinizulu, King of the Zulus, c. 1910

Humans are holistic beings with intricately intertwined parts. Healing an illness such as leprosy has multiple facets, as we look to cure the disease and heal the fear and despair that its diagnosis and stigma engenders. Emotional pain is inflicted upon its sufferers as they are avoided, rejected, and treated as if they were animals. Their own confusion and self-doubts bring on suicidal thoughts and depression. Spiritual pain is endured as they are forbidden to enter places of worship due to the prevailing belief that the disease's aetiology is their 'sinful' state. Economic pain ensues due to reduced ability to work from nerve damage, rejection by their employers or being put out by their family.

Health education about the disease, drug treatment and self-care are important factual and objective reason-orientated aspects of the healing process. However, these alone will not heal the deep-seated wounds that years of rejection have inflicted upon the person's emotions and spirit. To heal these deeper wounds people need healing of their personhood or self-image. ${ }^{1}$ 'Many tears have been shed. Those they have loved have turned against them. Now the way back seems hard and hazardous, and the heart shrinks from the prospect of yet another rebuff at the end of the effort.'

Correspondence to: M. Floyd-Richard (e-mail: bmrichard@ compuserve.com, Tel: +44 1744 23688) 
In October 1993, the Counselling Department at Green Pastures Hospital (GPH), Pokhara, Nepal was started to help heal and rebuild people psychologically and socially. A nurse and a counselling psychologist worked together to understand and respond to the counselling needs of the inpatients. Psychosocial assessments for all inpatients were provided and then individual counselling offered to those needing specific help in emotional, social, spiritual or reproductive health. Patients needing vocational training or an economic assessment were referred to the local Rehabilitation service (Partnership for Rehabilitation). Due to time restraints and the recurring themes of stigmatized patients we decided to conduct a pilot study on the efficacy of group counselling in dealing with stigmatization issues. We surmised that group counselling would help people to: develop relationships as they described their similar sufferings, educate them on the common effects of stigmatisation (ie. social isolation, depression and decreased self-esteem), and encourage them to think constructively on how they can begin to rebuild their self-esteem and thus, their lives.

\section{Materials and methods}

Groups composed of five to seven individuals meet for 2-h sessions each week for 5 weeks. They meet as single sex adult or children's groups. In these groups people are encouraged to remember things from three phases in their lives: before contracting leprosy, after contracting leprosy, and life as an inpatient at GPH. Themes that arise are despair and depression, stigmatization, reconciliation, dependency and rebuilding one's life. Due to the low literacy level of the inpatients, our discussions are supplemented by simple pictures used to further explain these themes.

A database was started including simple leprosy demographics and specific questions regarding WHO Impairment Scores, marital status, and family support. There were 22 counselling groups from March 1994 to February 1998. Seventy-four percent (86/117) had WHO impairment scores of 1 or 2 . Women had less family support than men.

Within the first week after admission patients are given a psychosocial assessment. If they demonstrate one or more of the following they are offered group therapy: their own recognition that their low self-esteem is due to stigmatization, they have been rejected by their families, or despondent but not clinically depressed. They are given a brief description of group therapy and their consent to join the group is requested.

The group therapy 5-week cycle follows the pattern described below.

\section{Week 1}

We sit in a circle on floor mats or chairs depending upon their physical needs. People are introduced to one another and data are collected. The group process is described and they are encouraged to be active participants in helping one another look at and build their selfesteem. They are told that telling others about their hurtful experiences is painful, but like operating on an ulcer is necessary, likewise, coming to resolution with the past hurts helps to gives new energy for building a future. People are then asked to close their eyes and remember in as much detail as possible what their life was like before leprosy. Then a few minutes later, what it was like when they first discovered they had leprosy. Followed by, what it was like over the last few months and years before they came to GPH. They are then asked 
to think about their first few days at GPH and then open their eyes. We ask someone to begin by telling us their life story. It often takes one person 30-40 min to tell their life story, so some people will need to tell their story in the second meeting.

\section{Week 2}

Most people seem to be more relaxed during this second session. Bonds begin to develop between patients as they hear others tell about their experiences of 'hate filled words from family and friends' and the ensuing isolation that occurred. Often someone will cry during the telling of their story. We encourage someone near them to show a sign of care for the person. In this context, women seem more easily able to put a hand on the person's shoulder or arm. Men, when asked to do so, will put a hand on the person's shoulder, but look less natural in doing so. We also allow time for the person to cry and get in touch with their pain. Many people, especially men, are hesitant when asked to share their story yet after doing so almost all of them are glad to have shared the story of their pain in living with leprosy. We summarize briefly at the end of each person's story and use feeling words to acknowledge the pain the person felt.

\section{Week 3}

Teaching and talking about the depression that came from their stigmatisation normalises their depressive feelings, and shows us their mental, emotional, and spiritual resources. As we explain the Cycle of Depression Chart (Figure 1) we refer back to their personal stories or ask for other examples from their lives. Encouragement is given to forgive those who have hurt them and be open again to relationships with these people and others. Some time is allowed for thinking who they want to forgive and writing that name(s) on a paper, or making Xs on a paper to show how many they want to forgive. These papers can they be put into a rubbish bin

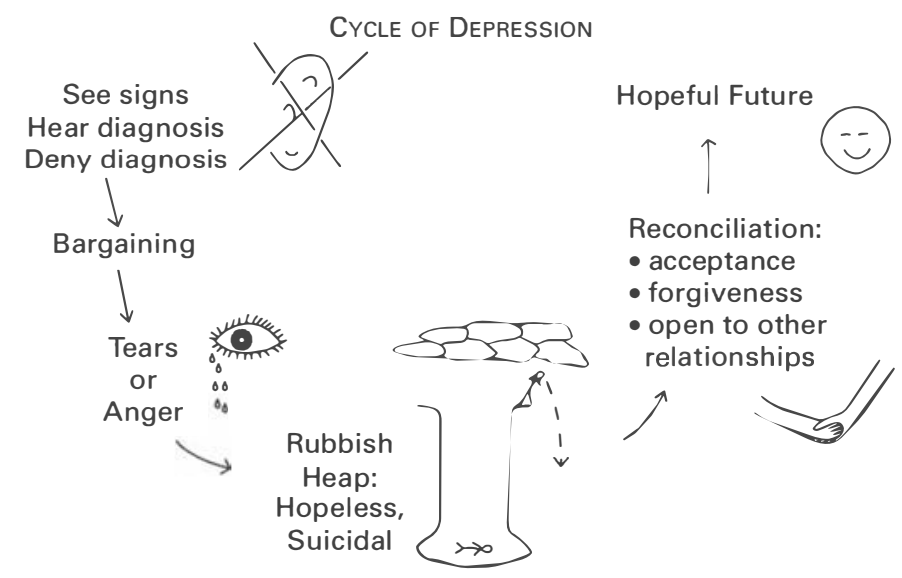

Figure 1. Cycle of depression. 
and burned to show that forgiving is finishing with the past hurts and having a clean heart to return home with.

Figure 1 shows our visual representation of the Cycle of Depression. The following information briefly describes each stage of the chart.

Denial - person hears they have leprosy and denies this diagnosis.

Bargaining - person tries to bargain with god(s) to take the disease away stating their intention to be more devout.

Tears or anger - people describe themselves as crying on their own for days/weeks once they realize the diagnosis is true. Anger, which is a common response to bad news in the west, is not common in Nepal, probably due to Hindu/Buddhist fatalistic belief.

Hopeless/suicidal - person feels hopeless. Suicidal thoughts such as jumping off a cliff, often come to their minds. They feel like 'rubbish or a non-person'. Heaviness, like a very cloudy day, covers any view of the sun (hope).

Reconciliation - person comes to peace about their situation.

Acceptance - they accept the positive and negative aspects of life with leprosy, its disfigurement and disability.

Forgiveness - they forgive those who have hurt them.

Open to others - are again open to develop old and new relationships.

Hopeful future - person has new hopeful vision for their future. They can again be a creative active participant in a community.

\section{Week 4}

We discuss the basic needs of humans, relationships with God, security/survival, significance and achievement. Then we look at WHO and WHAT they are dependent on in their lives (Table 1). Their past hierarchy of dependencies became imbalanced. The rejection they have encountered highlights their need to rethink and reset their dependencies. We then discuss options of HOW to meet their needs in the future.

\section{Week 5}

We ask people to describe how they viewed themselves before getting leprosy, after getting

Table 1. Hierarchy of factors that people are dependent on. Stigma challenges us to re-evaluate where we put our dependency. People internalize and rate these areas of dependency in various orders according to their age, disabilities, marital status, financial status, etc.

Place in the community

Friendships

Status/caste/profession

Health/job

Family/son(s)

Material wealth: house, animals, gold, possessions

Relationship with God: accepted and loved 
leprosy, after coming to GPH and as they think they might be back in their home setting. We then draw this on our white board as a visual image that symbolizes their fears and hopes. Discussion covering the ways in which they have tried to work through stigmatization and maintain relationships occurs addressing new approaches to relationships they might try when they return home. They often feel very stuck and unable to try new approaches. We talk about their relationships and new skills learned in the hospital.

\section{Discussion}

From our pilot study we conclude that group counselling is a time efficient and productive method of counselling to use in reducing the effects of stigmatization on people with leprosy. More people can be treated at one time thus using the scarce resource of a counsellor more efficiently. Group participants bond with one another and realize that they are not the only ones who suffer. They understand the 'cycles of depression' that they have previously gone through and discuss practical ideas for reaching a positive hope-filled life for themselves.

Although we believe that group counselling is an efficient and productive method to use for this group of people, our outcome measures are weak. Self-image is difficult to evaluate. It has no objective external scale by which to measure it, but rather a relative scale based on how a person sees themselves compared to those around them, and how others see and respond to them ${ }^{1}$. Therefore, the emotional effect of a person with leprosy's disease label or an ensuing impairment, may be out of proportion to the physical disability itself. Using an anxiety scale to test the group members on intake and exit from the group seemed the best method to test for efficacy, however no normative anxiety test is available for Nepal.

Thinking about 'who they are' is one important part in changing a person's low selfesteem. Valencia encourages sufferers to avoid self-pity and transcend their sickness. 'They should be taught to rethink their position in the community .... (and) positive ideas critical to their return to the folds of society, (that of) their original family and group affiliations. ${ }^{3}$ However, only thinking about their low self-esteem will not produce the desired changes of behaviour. Increasing people's ability to act-out their new stronger self-image could be enhanced by role plays of confident and assertive behaviour. These two characteristics are lacking in leprosy patients in the Philippines and Nepal and result in less authoritative and prestigious roles being given to them ${ }^{4}$. Valencia's ${ }^{3}$ study in the Philippines encourages us to believe that 'the patient has an equal and shared responsibility in reinforcing the negative attitudes of others toward him ... Self-stigma is caused by the patient's inability to assert themselves in family and community affairs, by their wilful consent to be denied access to places where non-affected people can go, and by their quiet and passive acquiescence to actions directed toward them. ... (therefore) they will cease to be significant people in the community.'

Another aspect of improving the group is that of having a 'mentor' for the group, one who has 'gone through the changes themself'. On four or five occasions there was one person in the group, who although very disabled, had been able to begin to re-develop their self-esteem. This person almost always had an active spiritual aspect to their life with an inner peace and a practical motivation to make the most of their situation. They seemed to have accepted their limitations and were realistic about what they could do to meet their needs. Training a person like this in basic group skills would be a useful tool that self-help groups frequently use.

Counselling alone will not improve the self-image and acceptance of persons with 
leprosy. Disabled people are more readily marginalized and rejected from the middle and lower economic groups because their families struggle to feed someone who cannot help produce food or income ${ }^{5}$. Helping the whole family in vocational and economic rehabilitation, would help the family earn enough and therefore, keep the person at home.

Health education for the client, family and community is also necessary to help rebuild the self-esteem of the person with leprosy. Discussions covering the following issues would be beneficial.

\section{The village as one family}

1. Acceptance of each person in the village is important. This will go against caste system hierarchy and purity beliefs and will need to be explained in its benefit to the whole community by its love and care for the individual who is a part of the whole, rather than its detriment to the whole community by their uncomfortableness, fear, and rejection of one of them. This is particularly true for how women are treated in a family that they have married into. Women had almost 3 times less family support than men or boys (women had $46.5 \%$ negative support, men $16 \%$ and boys $20 \%$ ). In our groups, husbands often divorced their wives after the wife contracted leprosy, but few wives of men with leprosy left them. A few women were put out to live with the animals and feed scraps 'like a dog' while the husband took another wife to live with him.

2. Allowing each person to have a role which benefits the entire village. Thereby, the entire village grows in confidence, efficiency, and output.

3. Impaired and stigmatized individuals may be able to continue in the roles they once had and this will benefit the family and community as these skills will not be lost. They may however, need a change of roles and the Health Worker could help the family/ community to look at which role(s) might be more suitable for them. They may need less strenuous roles or even times of convalescence, but they do need roles that they feel are important.

Group therapy is a good use of scarce counselling resources and we will continue to develop its use in GPH and hope to establish its efficacy in the future.

\section{References}

${ }^{1}$ Brand P. Coping with a chronic disease: the role of the mind and spirit. Patient Education and Counseling, 1995; 26: $107-112$.

2 Brand P. Coping with a chronic disease: the role of the mind and spirit. Patient Education and Counseling, 1995; 26: 109.

${ }^{3}$ Valencia LB. Social science research on social dimensions of leprosy: where are we going from here? Int J Lepr, 1988; 57: 849 .

${ }^{4}$ Cardinall RJ. At the feet of Lord Vishnu: an ethnographic study of leprosy in Nepal. Pamphlet published in 1982.

5 Kopparty SNM. Problems, acceptance and social inequality: a study of the deformed leprosy patients and their families. Lepr Rev, 1995; 66: 239-249. 